\title{
Nerve Blocks of the Head and Face - An Interactive Review of Techniques and Clinical Cases
}

\author{
K. J. Krishna Priyanka', S. Balachandar ${ }^{2}$ and S. Parthasarathy ${ }^{3}$ \\ 'Postgraduate Student, Department of Anesthesiology, Mahatma Gandhi Medical College and \\ Research Institute, Sri Balaji Vidyapeeth, Pillayarkuppam, Puducherry - 607402, India; \\ krishnakarpagaraj@gmail.com \\ ${ }^{2}$ Assistant Professor, Jawaharlal Institute of Postgraduate Medical Education and Research (JIPMER), \\ Karaikkal, Puducherry - 609602, India; amuchandru@ymail.com \\ 3 Professor, Department of Anesthesiology, Mahatma Gandhi Medical College and Research Institute, \\ Sri Balaji Vidyapeeth, Pillayarkuppam, Puducherry -607402, India; painfreepartha@gmail.com
}

\begin{abstract}
Regional anaesthesia is emerging either as a sole anaesthetic technique or as a supplement to general anaesthesia in different surgical conditions. With increasing incidence of systemic illnesses coming for operative procedures, the value of addition of nerve blocks to a routine anaesthetic technique assumes more significance in terms of decreasing morbidity. Usually, the anaesthesiologists are familiar with abdominal, chest and extremity blocks. As ultrasound is not friendly with head and face with bony prominences, the progress in this field is further hampered. In this narrative review, we will try to elaborate on a few useful nerve blocks of the head and face; the importance of ultrasound in viewing those nerves in the bony gaps will be discussed. The use of such techniques as either a perioperative analgesic or as an independent anaesthetic method along with the precautions to be followed in their administration will be highlighted.
\end{abstract}

Keywords: Anaesthesia, Face, Head, Nerve Blocks, Regional

\section{Introduction}

Regional anaesthesia of head and face are not commonly practiced due to multiple reasons. Extensive bony hindrances, difficulty in locating the nerves, the possible bony distortion of the ultrasound images, absence of training of such blocks in the routine postgraduate curriculum may be the possible causes of its limited usage than other peripheral nerve blocks. The neural blockade of the trigeminal nerve and their branches along with or without branches of superficial cervical plexus block has far reaching advantages in anesthesia and pain relief ${ }^{1}$. The trigeminal nerve block at the Meckel's cave is a separate topic and it is not discussed here. The glossopharyngeal nerve, branches of the trigeminal nerve, cervical plexus their identification, techniques to block them with their uses and possible use of ultrasound to identify certain nerves will be narrated in this short review. The target nerves for ophthalmic and dental surgeries are not detailed as they are commonly described in many textbooks.

\section{Scalp Block}

The whole soft tissue area of the scalp is supplied by the designated nerves as described below:

- From the front: supra trochlear and the supraorbital branches of the ophthalmic or the first division of the fifth cranial i.e. trigeminal nerve (V1). 
- From the side: the face is supplied by zygomaticofacial and zygomatico-temporal nerves which are branches of the V2: Auriculo-temporal branch of the mandibular nerve (V3) also supplies a part of it.

- From the back: 1 . The lesser occipital nerve is a branch of superficial cervical plexus, 2. the greater occipital nerve emerges from the cervical nerves with, and 3. a minimal contribution from the greater auricular nerve, a branch again of the cervical plexus. (Figure 1) The above are the three described nerves.

Uses: Its useful for sewing up lacerations of the scalp, for awake craniotomies ${ }^{2}$ and analgesic regimen for brain surgeries. As there are recurrent branches from trigeminal nerve to the dura mater which is pain sensitive, it's necessary to combine trigeminal nerve block with scalp block for brain interventions.
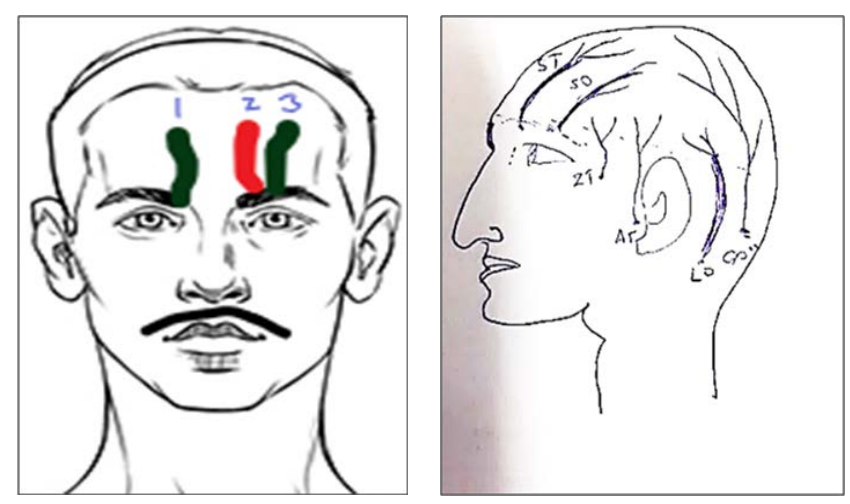

Figure 1. Showing distributions of different nerves.

\section{Technique}

\subsection{Supra Trochlear and the Supraorbital Nerves}

The supra trochlear nerve is usually blocked by one $\mathrm{ml}$ of local anesthetic drug just lateral to the medial canthus in the subcutaneous plane. The supra orbital nerve can be blocked in the supra orbital fossa (Figure 2 ). The ultrasound, kept in the plane of the pupil above the orbital rim will reveal a depression or a gap in the bone with pulsations. For USG guided injection, the needle ispricked from the lateral to medial with an in-plane approach to anaesthetize the supraorbital nerve ${ }^{3}$. The local anesthetic is dropped near the artery to block the nerve.

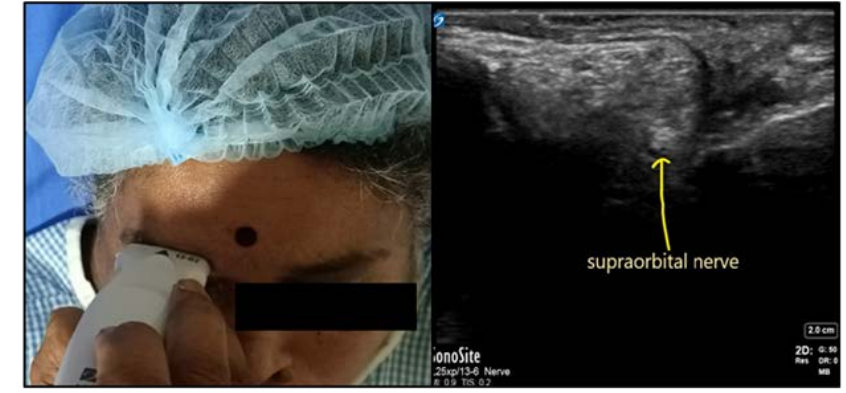

A

B

A: placement of probe, B: supraorbital nerve through the ultrasound

Figure 2. Ultrasound imaging for supraorbital nerve block.

\subsection{Zygomatico Temporal and Zygomatico Facial Nerves}

These nerves being branches of V2 can be blocked by an infiltration of local anesthetic in the subcutaneous plane lateral to the eyebrow towards the tragus ${ }^{4}$.

\subsection{Auriculo Temporal Nerve}

This nerve being a branch of $\mathrm{V} 3$ swirls around to supply the area above the auricle. After piercing the parotid gland, it carries sensations from the tragus and anterior part of the ear and also the part of the skin just over the temporalis muscle. This nerve can be blocked easily by ultrasound guidance. Keeping the probe in front of the tragus will reveal the superficial temporal vessel, posterior to which the nerve can be visualized ${ }^{5}$ (Figure 3). Deposition of 3- 4 $\mathrm{ml}$ of local anesthetic will anesthetize the nerve.

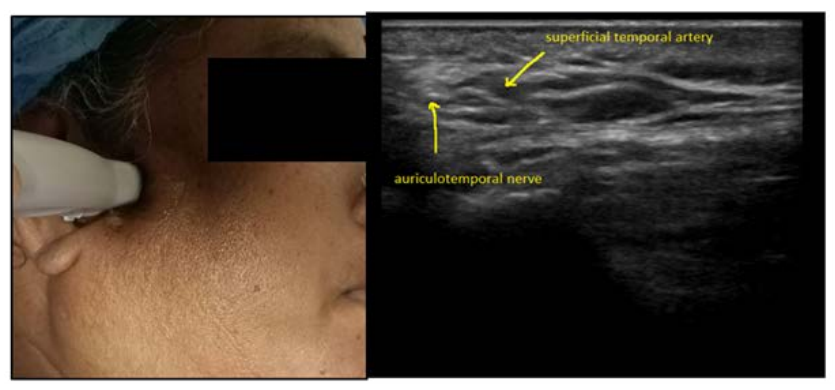

A

B

A: placement of probe between tragus and zygoma, $\mathrm{B}$ : auriculotemporal nerve close to the artery through the ultrasound

Figure 3. Ultrasound imaging for auriculotemporal nerve block. 


\subsection{Lesser Occipital, Greater Occipital and Greater Auricular Nerves}

Three in one infiltration: A single subcutaneous infiltration of local anesthetics from the level of greater occipital protuberance will block lesser occipital nerve, greater auricular nerve, which are branches of cervical plexus. It will also block the greater occipital nerve which comes directly from cervical spinal nerve. Both lesser and greater occipital nerves can also be visualized in ultrasound and blocked each with $1 \mathrm{ml}$ of the local anesthetic $\mathrm{c}^{6,7}$ (Figure 4).

Hence blockade of the above said nerves on both sides constitute a scalp block after which all soft tissue surgeries of the scalp can be done.

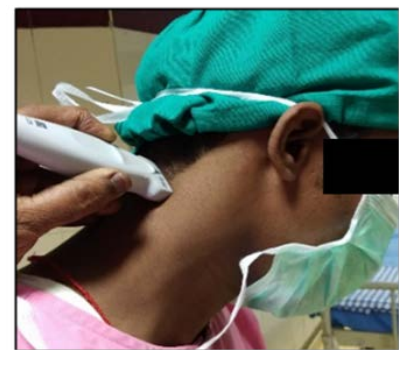

A

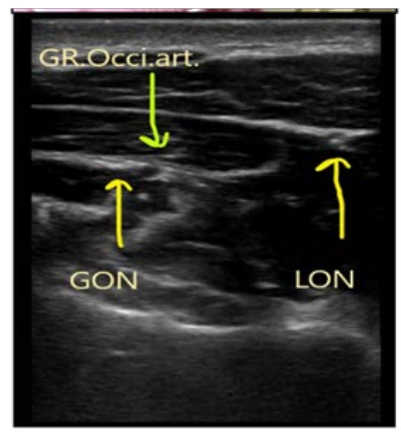

B
A: placement of probe B: greater and lesser occipital nerve through ultrasound. Greater occipital nerve near its artery (GON: Greater occipital nerve, LON: Lesser occipital nerve)

Figure 4. Ultrasound image for greater and lesser occipital nerve.

\section{Maxillary Nerve}

The maxillary nerve is the second branch of the fifth cranial nerve (V2). It courses in the lateral wall of cavernous sinus. It comes out of the skull through foramen rotundum and the comes to occupy the pterygopalatine fossa. The maxillary nerve leaves the pterygopalatine fossa through the infraorbital fissure and terminates as the infraorbital nerve in the orbital cavity. The nerve is purely sensory, It carries sensations from the upper lip, upper teeth, palate, roof of the pharynx, lower eyelid, cheek and the nose, It also innervates themaxillary, ethmoid and sphenoidalsinuses and a part of the meninges.

Technique $^{8}$ : Blockade of maxillary nerve can be done with or without the use of ultrasound.
- Needle in the mandibular notch

- Open and close the mouth to find the notch if in doubt

- Anterior to tragus

- Insert medially straight from lateral

- The pterygoid plate will be hit within $2 \mathrm{~cm}$ usually.

- Slid anterior and above

Deposit 5 - $10 \mathrm{ml}$ of local anesthetic (Figure 5).

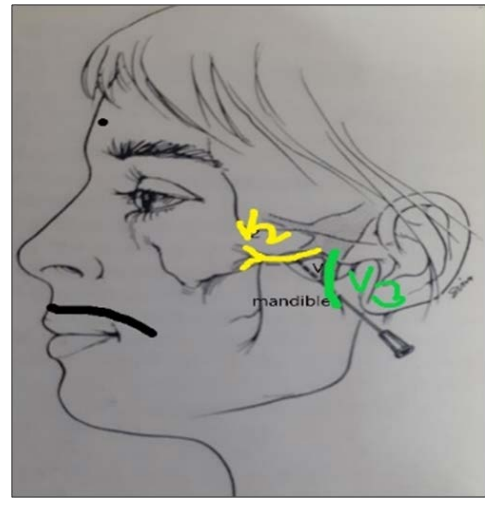

Figure 5. Shows the entry of needle and direction.

The maxillary nerve can be blocked with multiple indications.

- Trigeminal neuralgia limited to the second branch or a post-herpetic cause ${ }^{9}$

- Cluster headache

- Pain in the eye region, the nose, upper jaw, and gums or in simple terms unknown pain in the area of its sensory supply

Postoperative pain which occurs in the distribution of V2

- Pain after a dental procedure

- Occasionally used as a therapy for vasomotor rhinitis

\subsection{Infraorbital Nerve}

It is the terminal branch of the V2 emerging through the infraorbital foramen which is about $1 \mathrm{~cm}$ below the midpoint of the lower orbitalmargin.

Technique: The line of block is along the pupil. We need to palpate the infraorbital foramen just below the orbit in the face as a dip the needle is introduced just below the point of palpation until a bone contact is made. After that, the needle is withdrawn slightly and injected usually a maximal dose $3 \mathrm{ml}$ is enough ${ }^{10}$. An intraoral approach is 
also described ${ }^{11}$. The midpoint of the lower orbital margin is palpated and it is marked with the middle finger. The upper lip is picked with our left thumb and index finger and lifted. The needle is introduced above the second premolar tooth toward the infraorbital foramen (From the skin, the other hand is used as a guide) until a bony contact is made, and with drawn slightly to inject the drug. It is ideal to avoid the canal to prevent direct neural injection while compression after injection is needed for prevention of haematoma. Ultrasound guided injection is also feasible. The High Frequency Linear (HFL) transducer is placed directly over the body of the maxilla parallel to and $1 \mathrm{~cm}$ below the infraorbital margin (Figure 6a). Infraorbital foramen is seen asa gap on the maxillary bone through which the infraorbital nerve emerges along with a vessel (Figure $6 \mathrm{~b})^{12}$. The needle is introduced from the lateral to medial and the injection is made slowly to avoid blood vessels.

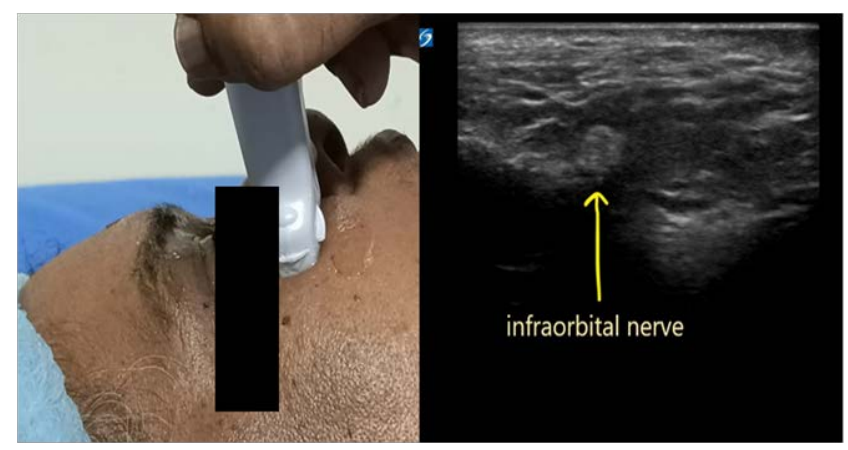

A

B

A: placement of probe B: infraorbital nerve through the ultrasound

Figure 6. Ultrasound imaging for infraorbital nerve block.

\subsection{Sphenopalatine Ganglion Block}

The Spheno-Palatine Ganglion (SPG) is a division of V2. It is a triangular parasympathetic autonomic ganglion, located superficially in the pterygopalatine fossa. The site is posterior to the middle nasal turbinate and anterior to the pterygoid canal.

Technique $^{13}$ (Figure 7): Sterile cotton swab (stick like), soaked well in Lignocaine jelly is introduced in the nostril, in an upward and backward direction till a resistance is felt. Inject local anesthetic along the side of stick, so that the drug can reach at the base of the medial turbinate. This is usually less than $5 \mathrm{~cm}$. After five minutes, the stick is redirected in an upward, lateral, and a little backward to target more surface. Again, inject local anesthetic in a similar fashion.

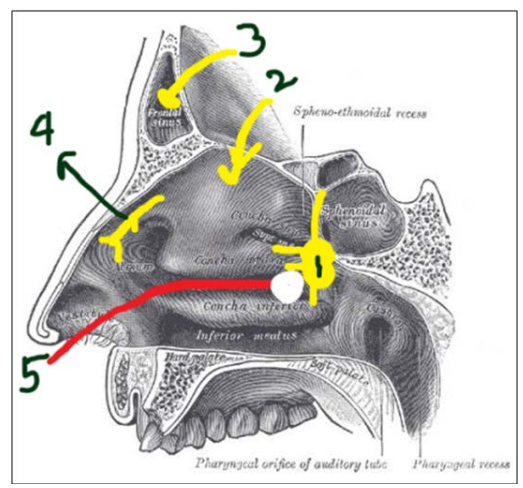

Figure 7. 1. Sphenopalatine ganglion. 2. Inferior orbital branches of V2. 3. Frontal nerve (V1). 4. Anterior ethmoidal branch (V1), and 5. Applicator soaked in local anesthetic).

\section{The Mandibular Nerve}

There are many indications of this nerve block from which a few are listed below:

- Differential diagnosis of either trigeminal neuralgia (usually pain in the anterior two thirds of the tongue) or glossopharyngeal neuralgia (pain in the posterior third of the tongue) Mandibular nerve block has no effect on glossopharyngeal neuralgia

- Tinnitus (the principle behind is that the otic ganglion has a few connections with the chorda tympani, the nerves of the pterygoid canal, and the medial pterygoid nerve)

- Trigeminal neuralgia in the third branch, a single injection may break the vicious cycle of neuropathic pain

- Trismus after a dental procedure

- Dental and maxillary surgeries - anesthetic dosages need to be with more volume and higher concentration

Technique: The needle is introduced from lateral to medial direction in the mandibular notch to hit the pterygoid plate similar to maxillary nerve block. But after hitting the plate, the needle is dipped slightly posterior. Electrostimulation of the masseter muscle can be added as an extra confirmation point for the needle position during blockade of $\mathrm{V} 3$, as this branch is a mixed nerve (Figure 8) ${ }^{14}$. 


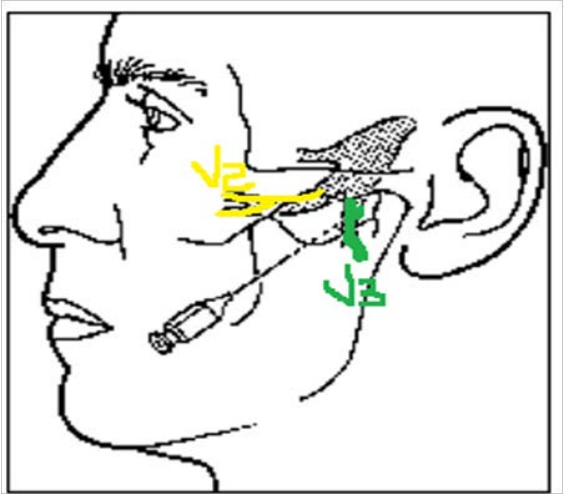

Figure 8. Shows the needle insertion point and direction for mandibular nerve block.

Ultrasound guidance ${ }^{15}$ (Figure 9) can be utilized to find the posterior portion of the pterygoid plate and drug deposition of around $5 \mathrm{ml}$ can be made. The sphenopalatine vessel is close to area of the nerve.

A: placement of probe B: mandibular nerve through the ultrasound

\subsection{Mental Nerve}

It is one of the terminal branches of V3. It supplies the skin of the chin and the skin and mucous membranes of the lower lip. It emerges in the chin through the mental foramen. The block has been described for entrapped mental nerve and lip surgeries.

Technique: With the ultrasound transducer positioned transverse, the mental foramen can be identified ${ }^{16}$ and blocked with one $\mathrm{ml}$ of $2 \%$ lignocaine (Figure 10).

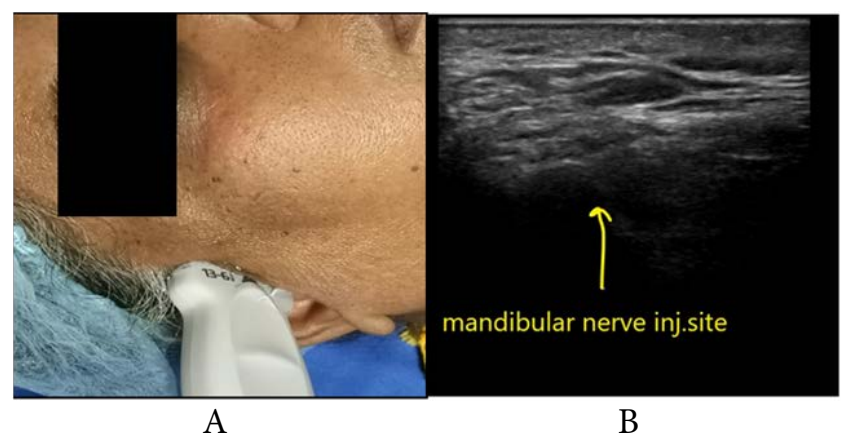

A: placement of probe B: mental nerve through the ultrasound

Figure 9. Ultrasound imaging for mandibular nerve block.

\subsection{Lingual Nerve}

Lingual nerve concerns with the sensory supply of anterior two thirds of the tongue. It conveys chorda tympani a branch from the facial nerve which provide staste sensation to the anterior two thirds of the tongue. It also carries the preganglionic fibers from chorda tympani to the submandibular ganglion and, in turn, supplying the submandibular and sublingual glands.

Technique: The point of insertion is distal to and 6-8 $\mathrm{mm}$ inferior to the lingual gingival margin of lower second molar $^{17}$ (Figure 11). The target is the lingual nerve site which is situated in the third molar area. The depth of penetration of the needle during the block should not exceed $8 \mathrm{~mm}$.

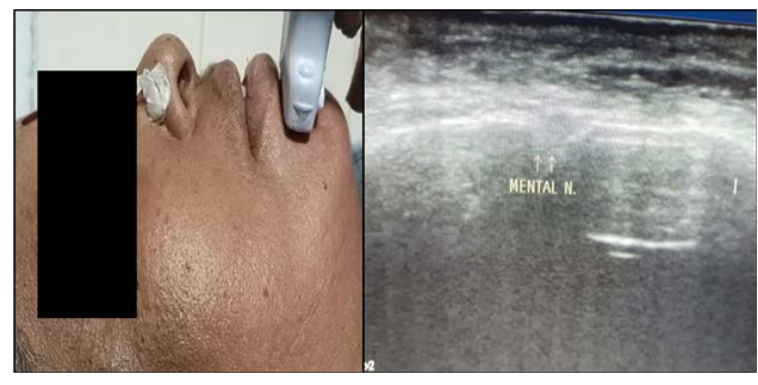

A

B

Figure 10. Ultrasound imaging for mental nerve block.

\subsection{Buccal Nerve}

The buccal nerve can be blocked for procedures involving the mucosa adjacent to the posterior molar teeth, e.g. placement of rubber dam clamp.

Technique $^{18}$ : The injection site is buccal to the third molar, with the needle just piercing $1-2 \mathrm{~mm}$ as the nerve lies just directly below the mucosa (Figure 11).

\subsection{Glossopharyngeal Nerve (IXth Cranial Nerve)}

The ninth cranial nerve innervates the middle ear, part of tongue and posterior part of pharynx. It also supplies the muscles of pharynx. It contains visceromotor, viscero sensory, and gustatory fibers. The block of this nerve is useful in diagnosing and differentiating glossopharyngeal neuralgia from trigeminal neuralgia. The intra oral approach to block is being used for perioperative pain relief in tonsillectomies ${ }^{19}$.

Techniques:

Extra oral approach:

1. Entry at Midpoint between mastoid and angle of the mandible

2. Styloid hit at $2.5 \mathrm{~cm}$

3. Slid posterior 


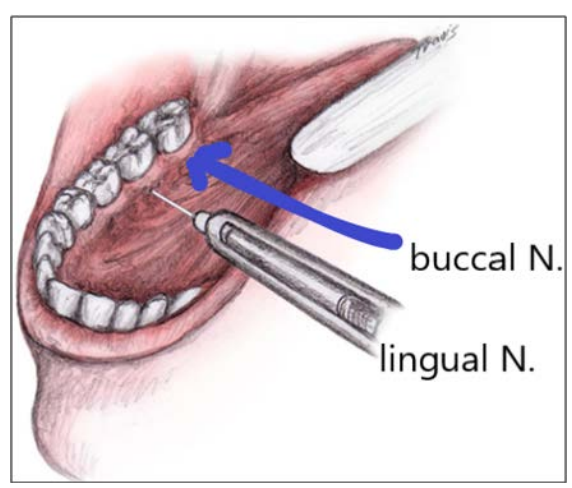

Figure 11. Shows the point of needle insertion for lingual and buccal nerve block.

4. Two $\mathrm{ml}$ of local anesthetic drug to be injected

This approach can be facilitated by the use of ultrasound ${ }^{20}$ (Figure 12).

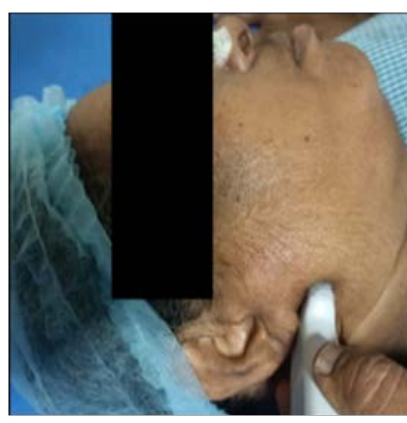

A

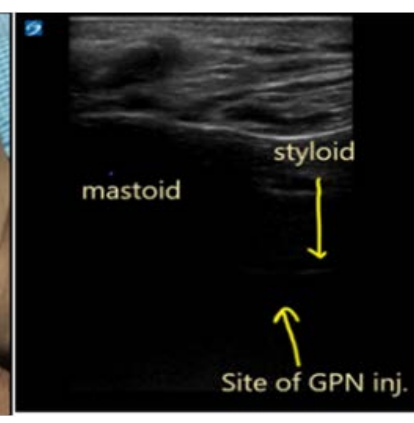

B
Figure 12. Ultrasound image for glossopharyngeal nerve.

A: placement of probe B: point of injection of local anesthetic behind the styloid process

The intraoral approach:

It can be done a little easier:

- Identify Posterior palate pharyngeal fold

- Use a Curved needle

- Submucous plane

- Aspiration

- Inject $2 \mathrm{ml}$ (Figure 13).

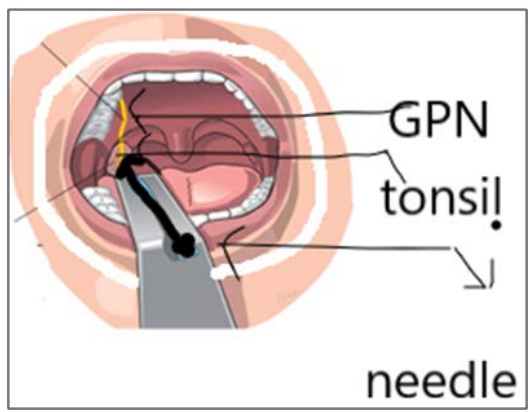

Figure 13. Shows the intra oral approach of glossophary ngeal nerve block.

\section{Some Clinical Scenarios and Discussion}

1. The parotid gland is supplied by the auriculo temporal nerve and the cervical plexus (greater auricular nerve). A combined block of the cervical plexus and the mandibular nerve may be enough to satisfactorily anaesthetize the parotid gland ${ }^{21}$----------.

2. Regarding the nasal sinuses, the frontal and ethmoidal ones are supplied by V1. The anesthesia for nasal surgeries can be accomplished by blocking the maxillary nerve when combined with nasocilliary nerve ${ }^{8}$.

3. It is very difficult to target the ophthalmic branch V1, but it has been suggested that slight angulation of the needle cephalad during maxillary nerve block may anaesthetize the nerve to conduct plastic surgeries of the face ${ }^{22}$.

4. The infraorbital nerve block, apart from perioperative analgesic technique can also be used as a sole anesthetic technique.

5. Regarding nerve block for tonsillectomy, the palatine tonsil is innervated by branches from V2, via the lesser palatine nerves, There are twigs from the tonsillarbranches of the (Nerve IX) glossopharyngeal nerve. Henceblocking maxillary and intraoral glossopharyngeal nerve with local spray may be helpful for avoiding general anesthesia. The temporomandibular joints need to be blocked to conduct with less discomfort.

\section{Conclusion}

Regional anesthesia of the head and face is still uncommonly used. Even with the ultrasound, the supplemental usage with General anesthesia seems to be infrequent. We suggest that such blocks and the training for the same to be part of the postgraduate curriculum and trainees should consider face blocks in appropriate cases without hesitancy. The use of ultrasound in a few blocks can be a boon to increase success and decrease the drug volume.

\section{Conflict of Interest}

\section{NIL}




\section{Financial Assistance}

NIL

All images are taken from the ultrasound machine 'SONOSITE X-PORTE' with a volunteer after informed consent.

\section{References}

1. Kumar A, Sinha C, Kumar A, Kumari P, Mukul SK. Ultrasound-guided trigeminal nerve block and its comparison with conventional analgesics in patients undergoing faciomaxillary surgery: Randomised control trial. Indian J. Anaesth. 2018 Nov; 62:871-75. https://doi.org/10.4103/ija. IJA_256_18. PMid: 30532323, PMCid: PMC6236796.

2. Burnand C, Joseph Sebastian. Anaesthesia for awake craniotomy. Continuing Education in Anaesthesia Critical Care and Pain. 2014 Feb 14; 1:6-11. https://doi.org/10.1093/ bjaceaccp/mkt024.

3. Allam Abdallah El-Sayed, Adham Aboul Fotouh Khalil, Basma Aly Eltawab, Wei-Ting Wu, Ke-Vin Chang. Ultrasound-guided intervention for treatment of trigeminal Neuralgia: An updated review of anatomy and techniques. Pain Research and Management. 2018 Apr; 1-9. https:// doi.org/10.1155/2018/5480728. PMid: 29808105, PMCid: PMC5902000.

4. Osborn I, Joseph S. Scalp block during craniotomy: A classic technique revisited. Journal of Neurosurgical Anesthesiology. 2010 Jul 22; 3:187-94. https://doi. org/10.1097/ANA.0b013e3181d48846. PMid: 20479675.

5. m SH, Hee JL, Jae SS, Kyunghoon M. Ultrasound-guided auriculotemporal nerve block for post-herpetic auriculotemporal neuropathy: A case report. Neurology Asia. 2017 Dec $4 ; 369-72$.

6. Binici O, Ufuk K, Murat S, Aysin A, Ismail Y. Ultrasound guided bilateral greater occipital nerve block for mass excision. Turkish Journal of Anesthesia and Reanimation. 2015 Dec; 43(6):437-39. https://doi.org/10.5152/ TJAR.2015.15975. PMid: 27366544, PMCid: PMC4894191.

7. Platzgummer H, Thomas M, Gerlinde MG, Christopher P, Christian W, Gerd B, Doris L-S. The lesser occipital nerve visualized by high-resolution sonography-normal and initial suspect findings. Cephalalgia. 2015 Aug; 35:81624. https://doi.org/10.1177/0333102414559293. PMid: 25414471.

8. Parthasarathy S. Anaesthetic management of bilateral nasal polypectomy in a patient with kartagener syndrome. Sri Lankan Journal of Anaesthesiology. 2012 Apr; 20(1):56-57. https://doi.org/10.4038/slja.v20i1.3305.

9. Parthasarathy S, Janani N. Maxillary nerve block - a useful supplementary technique in the management of trigemi- nal neuralgia: A case report. SBV Journal of Basic, Clinical and Applied Health Science. 2019 Mar; 2:43-44. https://doi. org/10.5005/jp-journals-10082-02109.

10. Boselli E, Lionel B, Caroline A-M, Gérard B, Nathalie D-J, Najia R, Delphine V-C, et al. Infraorbital and infratrochlear nerve blocks combined with general anaesthesia for outpatient rhinoseptoplasty: A prospective randomised, double-blind, placebo-controlled study. Anaesthesia Critical Care and Pain Medicine. 2016 Feb; 35:31-36. https://doi.org/10.1016/j.accpm.2015.09.002. PMid: 26549134.

11. Parthasarathy S, Indu K. Excision of right nasolabial cyst under intra oral infra orbital nerve block - A case report and a short review. Indian J. Clin. Anaesth. 2017; 4(1):14749.

12. Abdellatif AA, Ashraf EE, Khaled E. Ultrasound-guided infraorbital nerve block for cleft lip repair in pediatrics: A new technique for an old block. Ain-Shams Journal of Anesthesiology. 2018 Oct; 3. https://doi.org/10.1186/ s42077-018-0011-9.

13. Serdar E. Sympathetic Block of the Head and Neck. In: Prithvi Raj P, editor. Interventional Pain Management: Image Guided Procedure. 2nd ed. Philadelphia: Saunders Elsevier; 2008. 288-91.

14. Kumar N, Shashni S, Singh R, Jain A. Mandibular nerve block for peri-operative pain relief using a peripheral nerve stimulator: correspondence. Anaesthesia. 2011 Dec; 67(1):77-78. https://doi.org/10.1111/j.13652044.2011.06949.x. PMid: 22150491.

15. Jain G, Ghanshyam Y, Anil PS, Yashpal S, Dinesh KS. Efficacy of ultrasound-guided mandibular block in predicting safer anesthetic induction. Anesth. Essays. Res. 2016 May-Aug;10(2):184-88. https://doi.org/10.4103/02591162.176406. PMid: 27212744, PMCid: PMC4864673.

16. Park HG, Pyung GP, Won JK, Yong HP, Hyun K, Chong WB, Yong HJ, Young CW, Gill HK, Hwa YS. Ultrasoundassisted mental nerve block and pulsed radiofrequency treatment for intractable postherpetic neuralgia: Three case studies. The Korean Journal of Pain. 2014 Jan; 27(1):81-85. https://doi.org/10.3344/kjp.2014.27.1.81. PMid: 24478907, PMCid: PMC3903807.

17. Balasubramanian S, Elavenil P, Guruprasad T, Pathumai M, Simin A, Krishnakumar RVb. Efficacy of exclusive lingual nerve block versus conventional inferior alveolar nerve block in achieving lingual soft-tissue anesthesia. Annals of Maxillofacial Surgery. 2017 Nov;7(2):250-55. https://doi. org/10.4103/ams.ams_65_17. PMid: 29264294, PMCid: PMC5717903.

18. Drum M, Al R, Mike B. Long Buccal nerve block injection pain in patients with irreversible pulpitis. Oral Surgery, Oral Medicine, Oral Pathology, Oral Radiology 
and Endodontics. 2011 July; 112(1):e51-54. https://doi. org/10.1016/j.tripleo.2011.01.028. PMid: 21458333.

19. Ahmed SA, Amany FO. The effect of glossopharyngeal nerve block on post-tonsillectomy pain of children; randomized controlled trial. Anesth. Pain Med. 2019 Apr; 9(2):e90854. https://doi.org/10.5812/aapm.90854. PMid: 31341828, PMCid: PMC6614918.

20. Liu Q, Qing Z, Guoqiang T, Guanghong H. Ultrasoundguided glossopharyngeal nerve block via the styloid process for glossopharyngeal neuralgia: A retrospective study. Journal of Pain Research. 2019 Aug; 12:2503-10.
https://doi.org/10.2147/JPR.S214596. PMid: 31496791, PMCid: PMC6690851.

21. Parthasarathy S, Manohar R. Combined mandibular nerve block and superficial cervical plexus block for parotid gland surgery. British Journal of Pharmaceutical and Medical Research (BJPMR). 2017 Jan-Feb; 02(01):394-96.

22. Parthasarathy S, Manohar R. Single injection combined maxillary and ophthalmic nerve block for debridement of facial injuries. British Journal of Pharmaceutical and Medical Research (BJPMR). 2017 Jan-Feb; 02(01):384-87. 